Check for updates

Cite this: RSC Adv., 2017, 7, 38538

\title{
Improvement in thermostability of an alkaline lipase I from Penicillium cyclopium by directed evolution $\uparrow$
}

\author{
Yihan Liu, ${ }^{\text {acd }}$ Hao Liu, ${ }^{\text {ad }}$ Lin Huang, ${ }^{\text {abd }}$ Shuang Gui, ${ }^{\text {ad }}$ Dong Zheng, ${ }^{\text {bd Leibo Jia, }}$ \\ Yu Fu ad and Fuping Lu (D) *acd
}

Lipases have been used in a wide range of applications, and thermostable lipases are highly required. Lipase I $(\mathrm{PCL})$ from Penicillium cyclopium with alkali stability showed poor thermostability, resulting in a limited application in industrial processes with high temperatures. In this study, to expand the functionality of $\mathrm{PCL}$, the thermostability of PCL was enhanced through direct evolution with error-prone PCR. Using a high-throughput activity assay, the double mutant PCL (L41P/G47I) with improved thermostability was selected, and then the single mutants L41P and G47I were constructed via site-directed mutagenesis. The mutant PCLs exhibited an optimum temperature $5{ }^{\circ} \mathrm{C}$ higher than the wild-type (WT). WT showed no activity with incubation at $40{ }^{\circ} \mathrm{C}$ for $90 \mathrm{~min}$, whereas L41P, G47I, and L41P/G47I displayed $11 \%, 44 \%$, and $23 \%$ of their maximal activity after incubation at $45{ }^{\circ} \mathrm{C}$ for $60 \mathrm{~min}$. Meanwhile, the half-life at $45^{\circ} \mathrm{C}$ of L41P, G47I, and L41P/G47I was 7-, 13-, and 9-fold higher, respectively, than that of WT. Moreover, G47I, L41P/G47, L41P, and WT were successfully applied in the synthesis of ethyl propionate with conversions of $45 \%, 27 \%, 23 \%$, and $8 \%$. The studies of circular dichroism spectroscopy and fluorescence spectroscopy indicated the lower flexibility and higher compactness of the structure of the mutant PCLs as compared with WT. Combining these results and analysis of the three-dimensional structure modeling, the mechanism responsible for the improvement of the thermostability was elucidated, which demonstrated that Leu41Pro and Gly47/le could stabilize the structure of PCL through hydrophilic/ hydrophobic interactions, proline substitution, and helix propensity.

Received 6th June 2017
Accepted 13th July 2017
DOI: 10.1039/c7ra06307e
rsc.li/rsc-advances

\section{Introduction}

Lipases (triacylglycerol hydrolases, EC 3.1.1.3) can catalyze the hydrolysis of triacylglycerols to yield free fatty acids, diacylglycerols, and monoacylglycerols at oil-water interfaces and can assist in the synthesis of lipids by transesterification, esterification, and alcoholysis in organic solvents. ${ }^{1}$ Lipases have therefore been widely used in industrial applications, such as in food, detergent, pharmaceutical, paper making, cosmetic additive, textile, waste oil disposal, bioremediation, and biodiesel industries. ${ }^{2-10}$ However, most of these processes must be performed at a high temperature, which is a key factor for these successful industrial bioprocesses,${ }^{11}$ and can curtail the risk of

${ }^{a}$ Key Laboratory of Industrial Fermentation Microbiology, Ministry of Education, Tianjin 300457, P. R. China. E-mail: lyh@tust.edu.cn; Ifp@tust.edu.cn; Fax: +86 022 60602298; Tel: +8602260601958

${ }^{b}$ Tianjin Key Laboratory of Industrial Microbiology, Tianjin 300457, P. R. China 'National Engineering Laboratory for Industrial Enzymes, Tianjin 300457, P. R. China ${ }^{d}$ The College of Biotechnology, Tianjin University of Science and Technology, Tianjin 300457, P. R. China

$\dagger$ Electronic supplementary information (ESI) available. See DOI: 10.1039/c7ra06307e mesophilic microbial contamination, reduce the cost of external cooling, and enhance the substrate solubility and reaction rates. Therefore, lipases with higher thermostabilities and higher optimum temperatures for activity over their counterparts are highly required. ${ }^{12}$

Over the past decades, lipases have been isolated and purified from nature, including from mammalian, plant, bacterial, and fungal sources. ${ }^{13}$ In contrast with mammalian and plant lipases, microbial lipases are relatively inexpensive and preferred for commercial use due to the fact that they can be extracellularly produced by large-scale fermentation. ${ }^{14}$ In recent years, various microbial lipases have been successfully cloned, sequenced, expressed, and characterized, such as lipases derived from Bacillus subtilis, Pseudomonas mandelii, Yarrowia lipolytica, Penicillium expansum, and Aspergillus niger. ${ }^{15-19}$ However, most wild-type (WT) lipases showed poor thermostabilities, which limited their application in industrial processes with higher temperatures. Therefore, in order to improve the thermostability of lipases, their molecular structures were modified through protein engineering including directed evolution and site-directed mutagenesis..$^{20-23}$

Two lipases, named lipase I and lipase II, have been isolated from Penicillium cyclopium. Lipase I (PCL) was capable of 
hydrolyzing short-, medium-, and long-chain triacylglycerols and had low activity toward mono- and di-acylglycerols, while lipase II could hydrolyze mono- and di-acylglycerols but had almost no activity with triacylglycerols. ${ }^{24}$ Compared with lipase II, which had maximal activity at $\mathrm{pH} 7.0$ with a half-life of $55 \mathrm{~min}$ at $50{ }^{\circ} \mathrm{C},{ }^{25} \mathrm{PCL}$ showed stability over a broad $\mathrm{pH}$ range of 8.0-10.0 and at a temperature of $30{ }^{\circ} \mathrm{C}$ or below, ${ }^{26}$ indicating that PCL was an alkali-stable and thermolabile enzyme. To date, PCL has been cloned and expressed in Escherichia coli, and moreover, high-level expressed in Pichia pastoris. ${ }^{27,28}$ Nevertheless, the poor thermostability of PCL prevented it from being applied in industrial processes with higher temperatures. In recent years, although protein engineering techniques have been successfully applied to improve the thermostability of lipases by introducing extra disulfide bonds and through directed evolution, ${ }^{22,23,29}$ studies aiming to enhance the thermostability of PCL have so far been limited, resulting in little theoretical basis and background data of the structure-function relationship at high temperatures on PCL being obtained for site-directed mutagenesis. Compared to site-directed mutagenesis, directed evolution could be used to generate desired variants without detailed structure-function information. Therefore, directed evolution has become a powerful technique for altering the functions of the enzymes, including their activity, substrate specificity, stability, and stereoselectivity. ${ }^{30,31}$

Based on these reasons, mutant PCLs with improved thermostabilities and an optimum temperature for activity were engineered by directed evolution using error-prone PCR in the present study. Then, the enzymatic properties and kinetic parameters of the mutant PCLs were investigated, and esterification tests were carried out. Meanwhile, the secondary structure and tertiary structure combined with the threedimensional structure of the mutant PCLs were analyzed to elucidate the molecular mechanism for the thermostability of the mutant PCLs and improve our understanding of the structure-function relationship in the lipases adapted to high temperatures.

\section{Materials and methods}

\section{Strains, plasmid, and culture media}

Escherichia coli DH5 $\alpha$, E. coli BL21 (DE3), P. cyclopium (TCCC41684) and plasmid pET-22b(+) were preserved in our laboratory. E. coli DH5 $\alpha$ and E. coli BL21 (DE3) were used as hosts for the various plasmid constructions and the expression of recombinant proteins, respectively. $P$. cyclopium was cultivated at $28{ }^{\circ} \mathrm{C}$ in Czapek-Dox medium $\left(\mathrm{NaNO}_{3}, 3 \mathrm{~g} \mathrm{~L}^{-1}, \mathrm{~K}_{2} \mathrm{HPO}_{4} 1 \mathrm{~g} \mathrm{~L}^{-1}\right.$, $\mathrm{MgSO}_{4} \cdot 7 \mathrm{H}_{2} \mathrm{O} 0.5 \mathrm{~g} \mathrm{~L}^{-1}, \mathrm{KCl} 0.5 \mathrm{~g} \mathrm{~L}^{-1}, \mathrm{Fe}_{2} \mathrm{SO}_{4} 0.01 \mathrm{~g} \mathrm{~L}^{-1}$, and saccharose $30 \mathrm{~g} \mathrm{~L}^{-1}$ ), and all bacteria were cultivated at $37^{\circ} \mathrm{C}$ in Luria-Bertani (LB) medium (bactotryptone $10 \mathrm{~g} \mathrm{~L}^{-1}$, yeast extract $5 \mathrm{~g} \mathrm{~L}^{-1}$, and $\left.\mathrm{NaCl} 10 \mathrm{~g} \mathrm{~L}^{-1}\right)$. Ampicillin $\left(100 \mu \mathrm{g} \mathrm{mL}^{-1}\right)$ was added to the growth medium when necessary.

\section{Cloning of the mature PCL gene}

Total RNA was extracted from $P$. cyclopium using a Fast RNA extraction kit (Bioteke, Beijing, China) followed by reverse transcriptase polymerase chain reaction (RT-PCR) using Thermo OneStep RT-PCR Kit (Bioteke). The PCL gene ( $p c l)$ encoding for the mature peptide of native PCL was amplified by PCR using the cDNA from P. cyclopium as a template. After the sequencing of $\mathrm{pcl}$, the codon-optimized $\mathrm{pclm}$ was synthesized (BGI, Shenzhen, China) by replacing the rare codon in the $p c l$ sequence according to the preferred codon usage of $E$. coli, which was beneficial in improving the expression level of $\mathrm{pcl}$ in E. coli. Then, pclm was amplified using the following primers: primer P1 5'-CGCGGATCCGGCAACCGCAGACGCAGCAG-3' ${ }^{\prime}$ and primer P2 5'-CCCAAGCTTACTCAGATAACCGCAACCTGCCGTC$3^{\prime}$ with the restriction sites Bam HI and HindIII (underlined). The PCR-amplified product was purified using a gel extraction kit (Omega, Norcross, Georgia, USA) and cloned into the BamHI and HindIII site of pET-22b(+), and the resulting plasmid was designated as pET-pclm.

\section{Construction of error-prone PCR library}

The recombinant plasmid pET-pclm was used as a template for error-prone PCR. The one hundred microlitre reaction mixture was composed of $10 \mathrm{ng}$ of template DNA, $10 \mu \mathrm{mol} \mathrm{L}{ }^{-1}$ of P1, 10 $\mu \mathrm{mol} \mathrm{L}{ }^{-1}$ of P2, $1 \times$ PCR buffer, $0.2 \mathrm{mmol} \mathrm{L}^{-1} \mathrm{dATP}, 0.2 \mathrm{mmol}$ $\mathrm{L}^{-1}$ dGTP, $1 \mathrm{mmol} \mathrm{L}{ }^{-1}$ dTTP, $1 \mathrm{mmol} \mathrm{L}^{-1} \mathrm{dCTP}, 5 \mathrm{mmol} \mathrm{L}^{-1}$ $\mathrm{MgCl}_{2}, 0.25 \mathrm{mmol} \mathrm{L}^{-1} \mathrm{MnCl}_{2}$, and $5 \mathrm{U}$ Taq DNA polymerase (Tiangen, Beijing, China). The PCR was carried out at $95{ }^{\circ} \mathrm{C}$ for 5 min followed by 30 cycles at $94{ }^{\circ} \mathrm{C}$ for $30 \mathrm{~s}, 55^{\circ} \mathrm{C}$ for $30 \mathrm{~s}$ and $72{ }^{\circ} \mathrm{C}$ for $1 \mathrm{~min}$ followed by $10 \mathrm{~min}$ at $72{ }^{\circ} \mathrm{C}$. The purified products of error-prone PCR digested by BamHI-HindIII were inserted into the BamHI-HindIII site of pET-22b(+) with the 6-His tag at the $\mathrm{C}$ terminus for purification, and the resulting plasmids were designated as pET-mpclms. The plasmids were transformed into competent $E$. coli $\mathrm{DH} 5 \alpha$ by electroporation. Subsequently, the plasmids extracted from the colonies of $E$. coli DH5 $\alpha$ were transformed into competent E. coli BL21 (DE3) for protein expression. The resultant clones, comprising the errorprone PCR library, were plated on LB agar plates with ampicillin $\left(100 \mu \mathrm{g} \mathrm{mL}{ }^{-1}\right)$ and incubated at $37^{\circ} \mathrm{C}$ for $12 \mathrm{~h}$.

\section{Screening of the mutant library}

After overnight growth on the plate, the colonies were picked with sterile toothpicks and grown in 96-well plates containing LB medium supplemented with $100 \mu \mathrm{g} \mathrm{mL}^{-1}$ ampicillin. The 96well plates were incubated at $160 \mathrm{rpm}$ and $37^{\circ} \mathrm{C}$ until the $\mathrm{OD}_{600}$ value reached 0.6 , followed by the addition of isopropyl- $b$-D-1thiogalactopyranoside (IPTG) at a final concentration of $0.5 \mathrm{mmol} \mathrm{L}{ }^{-1}$ to induce the expression of the WT and mutant PCLs. After incubation at $16{ }^{\circ} \mathrm{C}$ for $16 \mathrm{~h}$, the supernatant of each culture was collected by centrifugation at $5000 \times g$ for $10 \mathrm{~min}$ at $4{ }^{\circ} \mathrm{C}$ and transferred onto two identical plates. One of the plates was directly assayed at $25{ }^{\circ} \mathrm{C}$, whereas the second plate was incubated at $40{ }^{\circ} \mathrm{C}$ for $30 \mathrm{~min}$ in a moist chamber. After incubation, the plate was cooled on ice for 15 min followed by an enzyme activity assay at $25{ }^{\circ} \mathrm{C}$. The initial activity of the WT and mutant PCLs without heat treatment and residual activity after incubation at $40{ }^{\circ} \mathrm{C}$ was determined according to the modified method of Sigurgísladóttir et al. ${ }^{32}$ The reaction was carried out 
at pH 8.0 using $p$-nitrophenyl laurate (Sigma-Aldrich, Darmstadt, Germany) as the substrate at $25{ }^{\circ} \mathrm{C}$ for $10 \mathrm{~min}$. As a result of the enzymatic hydrolysis of the substrate, $p$-nitrophenol would be released and monitored by measuring the absorbance at $405 \mathrm{~nm}$. One unit of enzyme activity was defined as the amount of enzyme that liberates $1 \mu$ mole of $p$-nitrophenol from $p$-nitrophenyl laurate per min under standard assay conditions. By comparing the ratio between the initial activity and residual activity of each clone, the positive mutants with improved thermostability were selected.

\section{Site-directed mutagenesis}

The mutant PCL genes, with residues Leu41Pro and Gly47Ile, were constructed with plasmid pET-pclm as the template by sitedirected mutagenesis using a standard overlap extension PCR technique. The primer P1 and P2 were used to amplify the full length mutant PCL genes. The mutation Leu41Pro was created using sense primer P3: 5'-CAAACGCATCTACGACC $(\underline{\mathrm{T}} \rightarrow \underline{\mathrm{C}}) \underline{\mathrm{G}}$ GTTACCGATACCAACG- $3^{\prime}$ and anti-sense primer P4: 5'-CGTTGGTATCGGTAAC $\underline{C}(\underline{\mathrm{A}} \rightarrow \underline{\mathrm{G}}) \underline{\mathrm{G} G T C G T A G A T G C G T T T G}-3^{\prime}$, and mutant Gly47Ile was created using sense primer P5: $5^{\prime}$-CCTGGTTACCGATACCAAC $(\underline{\mathrm{G}} \rightarrow \underline{\mathrm{A}})(\underline{\mathrm{G}} \rightarrow \underline{\mathrm{T}}) \underline{\mathrm{T} T T T G T T G G C T A}$ CAGCACC-3' and anti-sense primer P6: 5'-GGTGCTGTA GCCAACAAA$(\underline{\mathrm{C}} \rightarrow \underline{\mathrm{A}})(\underline{\mathrm{C}} \rightarrow \underline{\mathrm{T}})$ GTTGGTATCGGTAACCAGG-3'. The mismatched sites of the site-directed mutagenesis are underlined. The mutant genes digested by BamHI-HindIII were inserted into the same endonuclease sites of pET-22b(+) to generate the recombinant plasmids pET-l41p and pET-g47i, and the resulting plasmids were transformed into competent $E$. coli DH5 $\alpha$. After being analysed by digestion with restriction enzymes and by DNA sequencing, the plasmids were transformed into $E$. coli BL21 (DE3) for protein expression.

\section{Expression and purification of PCLS}

The gene fragments coding for the WT and mutant PCLs were expressed in E. coli BL21 (DE3), harboring the plasmids pET$p c l m$, pET-l41p, pET-g47i, and pET-l41p/g47i, for functional analysis of the recombinant proteins WT, L41P, G47I, and L41P/ G47I. Recombinant E. coli BL21 (DE3) was grown at $37{ }^{\circ} \mathrm{C}$ for $12 \mathrm{~h}$ in LB media in the presence of ampicillin $\left(100 \mu \mathrm{g} \mathrm{mL} \mathrm{m}^{-1}\right)$. Then $1 \mathrm{~mL}$ of the culture was transferred to $50 \mathrm{~mL}$ of $\mathrm{LB}$ media containing $100 \mu \mathrm{g} \mathrm{mL}{ }^{-1}$ ampicillin. When the culture reached an $\mathrm{OD}_{600}$ of $0.6-0.8$, the cells were cultivated at $16{ }^{\circ} \mathrm{C}$ with shaking at $160 \mathrm{rpm}$ by the addition of a final concentration of $0.5 \mathrm{mmol} \mathrm{L}^{-1}$ IPTG. After cultivation for $16 \mathrm{~h}$, the cells were collected and disrupted by ultrasonication, and the lysates were centrifuged at $40000 \times g$ at $4{ }^{\circ} \mathrm{C}$ for $30 \mathrm{~min}$ and loaded onto a Ni-NTA agarose gel column equilibrated with lysis buffer $\left(10 \mathrm{mmol} \mathrm{L}^{-1}\right.$ sodium phosphate, $300 \mathrm{mmol} \mathrm{L}^{-1} \mathrm{NaCl}$ and $20 \mathrm{mmol} \mathrm{L}^{-1}$ imidazole, $\mathrm{pH}$ 7.4). After washing, the target protein was eluted using a linear imidazole gradient (100$500 \mathrm{mmol} \mathrm{L}^{-1}$ ) in the same buffer. The purity of the recovered samples was analyzed by sodiumdodecyl sulfate-polyacrylamide gel electrophoresis (SDS-PAGE). The protein concentration was determined by the Bradford method (1976), using bovine serum albumin as a standard..$^{33}$

\section{Activity assays of PCLs}

The assay for lipase activity was performed according to the Chinese Industrial Standard (GB-T 23535-2009). $1 \mathrm{~mL}$ of the WT and mutant PCLs were added to the substrate solution containing $4 \mathrm{~mL}$ of emulsified olive oil (1 vol olive oil and $3 \mathrm{vol} 1.0 \%$ $(\mathrm{w} / \mathrm{v})$ polyvinyl alcohol were mixed with a blender) and $5 \mathrm{~mL}$ of $50 \mathrm{mmol} \mathrm{L}^{-1}$ glycine-NaOH buffer (pH 10.0). After incubation for $10 \mathrm{~min}$ at $25{ }^{\circ} \mathrm{C}$, the reaction was terminated by the addition of $15 \mathrm{~mL}$ of ethanol. The level of fatty acid release was determined by titration with $50 \mathrm{mmol} \mathrm{L}^{-1} \mathrm{NaOH}$ solution. One unit of lipase activity was defined as the release of $1 \mu \mathrm{mol}$ of fatty acid per minute.

\section{Characterization of PCLS}

The optimum temperature of the WT and mutant PCLs was determined by carrying out the enzyme assay at different temperatures $\left(15-40{ }^{\circ} \mathrm{C}\right)$ in the $50 \mathrm{mmol} \mathrm{L}^{-1}$ glycine- $\mathrm{NaOH}$ buffer ( $\mathrm{pH} 10.0$ ) for $10 \mathrm{~min}$. To determine the optimum $\mathrm{pH}$, the activity of the WT and mutant PCLs was measured at $25{ }^{\circ} \mathrm{C}$ using the $50 \mathrm{mmol} \mathrm{L}^{-1}$ sodium glycine-NaOH buffer $(\mathrm{pH} 9.0-$ 11.0). The activities of the WT and mutant PCLs at the optimum temperature and optimum $\mathrm{pH}$ were taken as $100 \%$, respectively.

To determine the thermostability of the WT and mutant PCLs, the enzymes were incubated at various temperatures $\left(35^{\circ} \mathrm{C}, 40^{\circ} \mathrm{C}\right.$, and $\left.45^{\circ} \mathrm{C}\right)$ without substrate, for different times $(30,60,90$, and $120 \mathrm{~min})$ in the $50 \mathrm{mmol} \mathrm{L}^{-1}$ sodium phosphate buffer (pH 8.0). The pH stability of the WT and mutant PCLs was determined by incubating the enzyme at various $\mathrm{pH}$ levels (9.0, 10.0 , and 11.0) without substrate for different times $(40,80$, and $120 \mathrm{~min}$ ) in the $50 \mathrm{mmol} \mathrm{L}^{-1}$ glycine-NaOH buffer at $30{ }^{\circ} \mathrm{C}$. After cooling the treated enzyme samples on ice for $10 \mathrm{~min}$, the residual activity was determined based on the standard enzyme assay method. The original activities of the WT and mutant PCLs without preincubation were taken as $100 \%$, respectively.

\section{Kinetic parameters of PCLS}

The kinetic parameters of the WT and mutant PCLs were measured according to the described method from "Screening of the mutant library". The assay used to determine the kinetic parameters involved processing the reaction at $\mathrm{pH} 8.0$ and $30{ }^{\circ} \mathrm{C}$ using $p$-nitrophenyl caprylate, $p$-nitrophenyl laurate, and $p$-nitrophenyl palmitate as the substrates with different concentrations $\left(0.5-9.0 \mathrm{mmol} \mathrm{L}^{-1}\right)$. The data were fitted to the Michaelis-Menten equation using Origin 8.0 (Northampton, MA, USA) to generate estimates of the $k_{\text {cat }}$ and $K_{\mathrm{m}}$ values, which were plotted and are shown in ESI Fig. S1-S3. $\dagger$

\section{Synthesis of ethyl propionate}

The reactions for ethyl propionate synthesis were conducted in $100 \mathrm{~mL}$ capped flasks with a $15 \mathrm{~mL}$ reaction medium ( $n$-hexane, $n$-pentane, $n$-heptane, and $n$-octane) containing ethanol ( 0.20 , $0.25,0.30,0.35,0.40,0.45$, and $0.50 \mathrm{~mol} \mathrm{~L}^{-1}$ ), propionic acid $\left(0.20,0.25,0.30,0.35,0.40,0.45\right.$, and $\left.0.50 \mathrm{~mol} \mathrm{~L}^{-1}\right)$, molecular sieves, and freeze-dried PCL (800 U, $1200 \mathrm{U}, 1600 \mathrm{U}$, and 2000 $\mathrm{U})$. The reactions were carried out at different temperatures 
$\left(30{ }^{\circ} \mathrm{C}, 35^{\circ} \mathrm{C}, 40{ }^{\circ} \mathrm{C}\right.$, and $\left.45^{\circ} \mathrm{C}\right)$ with shaking at $150 \mathrm{rpm}$ for 16 , $20,24,28,32$, and $36 \mathrm{~h}$. The substrates and solvent were kept anhydrous by routinely adding molecular sieves.

Ethyl propionate was confirmed through chromatographic analyses of the samples on an Agilent 7890A gas chromatography (GC) system (Agilent Technologies, Santa Clara, California, USA) with a HP-5MS column (Agilent Technologies) [60 $\mathrm{m}$ (length) $\times 0.32 \mathrm{~mm}$ (inner diameter), $1.0 \mu \mathrm{m}$ (film thickness)]. Helium was used as the carrier gas with the flow rate at 1 $\mathrm{mL} \mathrm{min}^{-1}$. The conditions employed in the GC were as follows: maintenance at $50{ }^{\circ} \mathrm{C}$ for $3 \mathrm{~min}$, then increased to $240{ }^{\circ} \mathrm{C}$ at a rate of $6^{\circ} \mathrm{C} \min ^{-1}$ and held for $3 \mathrm{~min}$. The mass spectrometry (MS) detector (Agilent 5975C) was used at an electron voltage of $70 \mathrm{eV}$ and ion-source temperature of $230^{\circ} \mathrm{C}$. The samples were injected by the instrument's auto sampler with an injection volume of $1 \mu \mathrm{L}$. Identification of the compounds was conducted using the Mass Spectral Database (NIST 2.0) and authentic standards. The yield (\%) of methylacetic and ethyl alcohol to ethyl propionate was defined by the following equation:

Ethyl propionate conversion $(\%)=$ propionic acid amount transformed to ethyl propionate/total propionic acid amount $\times 100 \%$.

\section{Circular dichroism spectroscopy}

The far-UV CD spectra over the range of 190-260 $\mathrm{nm}$ were measured to monitor the secondary structure of the WT and mutant PCLs using a MOS-450 CD spectropolarimeter (BioLogic, Grenoble, France) equipped with a Peltier-type temperature controller and thermostatized cuvette cell linked to a thermostatic bath. The spectra were registered using a scan rate of $60 \mathrm{~nm} \mathrm{~min}{ }^{-1}$, bandwidth of $1 \mathrm{~nm}$, and response of $1 \mathrm{~s}$. The measurement was carried out in a quartz cuvette of $1 \mathrm{~mm}$ path length with $0.02 \mathrm{mg} \mathrm{mL}^{-1}$ protein solutions. In order to explore the effect of temperature on the CD spectra of the WT and mutant PCLs, the enzymes were incubated at $45{ }^{\circ} \mathrm{C}$ without substrate for $60 \mathrm{~min}$ in $50 \mathrm{mmol} \mathrm{L}^{-1}$ sodium phosphate buffer (pH 8.0). The spectrum of a system containing buffer $(50 \mathrm{mmol}$ $\mathrm{L}^{-1}$ sodium phosphate buffer, $\mathrm{pH}$ 8.0) only was measured as a blank. Analysis of the CD data was performed using the Dichroweb website: http:/www.dichroweb.cryst.bbk.ac. Each spectrum presented was an average of three measurements (analysis program SELCON3, reference set 7).

\section{Fluorescence spectroscopy}

Spectrofluorometric analysis was performed using a F-7000 Spectrofluorometer (Hitachi, Tokyo, Japan). The protein solutions were used with a concentration of $0.02 \mu \mathrm{g} \mathrm{mL}^{-1}$ and placed in a $10 \times 10$ $\mathrm{mm}$ cuvette. For determining the effect of temperature on the fluorescence spectroscopy of the WT and mutant PCLs, the enzymes were treated with incubation at $45{ }^{\circ} \mathrm{C}$ in the absence of substrate for $60 \mathrm{~min}$ in $50 \mathrm{mmol} \mathrm{L}^{-1}$ sodium phosphate buffer $(\mathrm{pH}$ 8.0). The intrinsic fluorescence emission spectra were acquired ranging from $300 \mathrm{~nm}$ to $400 \mathrm{~nm}$ with an excitation wavelength of $290 \mathrm{~nm}$. The excitation and emission slits were both set at $5 \mathrm{~nm}$. Each spectrum presented was an average of three measurements.

\section{Computer modeling method}

The three-dimensional models of the WT and mutant PCLs were built by a Swiss-Model server (http://swissmodel.expasy.org/) and PyMOL molecular graphic system with PEL (PDB code: $3 \mathrm{G} 7 \mathrm{~N}$ ) as the template.

\section{Results and discussion}

Screening of mutant library and site-directed mutagenesis of PCL

The strategy for screening the mutant PCLs was based on the residual hydrolyzing activity of the lipid after incubation at high temperatures. About 2700 clones from the mutant library (nearly 5800 clones) were screened to identify the mutants with increased thermostability. During the initial screening using 96-well plates, 5 mutants exhibited a higher thermostability than WT at $40{ }^{\circ} \mathrm{C}$. These mutants were further cultured in shake-flasks to characterize the enzymatic property, and one mutant that showed improved thermostability without compromising the activity was selected. Sequencing analysis revealed that the selected one had been mutated at two amino acid positions (Leu41Pro and Gly47Ile). The nucleotide sequence alignment of the selected mutant PCL gene with the WT displayed the three mutation sites resulting in the substi-

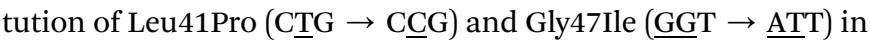
the amino acid sequence. Subsequently, the single-site mutation with Leu41Pro and Gly47Ile was generated by site-directed mutation.

\section{Expression and purification of WT and mutant PCLs}

The lipase activity of the WT and mutant PCLs was detected in the supernatant lysate of BL21/pET-pclm, BL21/pET-l41p, BL21/ pET- $g 47 i$, and BL21/pET-l41p/g47i after cell disruption by ultrasonication, and there was no lipase activity in the supernatant lysate of $E$. coli BL21 (DE3) harboring the empty plasmid pET-22b(+) (BL21/pET22b). The WT and mutant PCLs displayed a distinct band of approximately $32 \mathrm{kDa}$ in the SDS-PAGE (Fig. 1A, lanes 2-5), which was identical in size to the purified proteins (Fig. 1B, lanes 1-4). No corresponding band was shown with the control strain BL21/pET22b (Fig. 1A, lane 1). After Niaffinity chromatography, the specific activities of the purified WT and mutant PCLs were determined to be $1193 \mathrm{U} \mathrm{mg}^{-1}, 1028$ $\mathrm{U} \mathrm{mg}{ }^{-1}, 1185 \mathrm{U} \mathrm{mg}^{-1}$, and $1038 \mathrm{U} \mathrm{mg}^{-1}$, and they formed a single band with a purity of at least $95 \%$, which was beneficial to functional analysis.

\section{Enzymatic property of WT and mutant PCLS}

The optimal $\mathrm{pH}$ for WT and mutant PCLs was found to be 10.0 (Fig. 2A). As shown in Fig. 2B-D, the pH stability of the mutant PCLs was similar to that of WT at $\mathrm{pH} 9.0,10.0$, and 11.0, indicating that there was no distinct difference in the alkali resistance between the WT and mutant PCLs after mutation.

The mutant PCLs showed the highest activity at $30^{\circ} \mathrm{C}$, which was $5{ }^{\circ} \mathrm{C}$ higher than that of the WT (Fig. 3A). As shown in Fig. 3B-D, compared with WT, which exhibited no activity after incubation at $40{ }^{\circ} \mathrm{C}$ for $90 \mathrm{~min}$ and at $45^{\circ} \mathrm{C}$ for $30 \mathrm{~min}, \mathrm{~L} 41 \mathrm{P}$, 

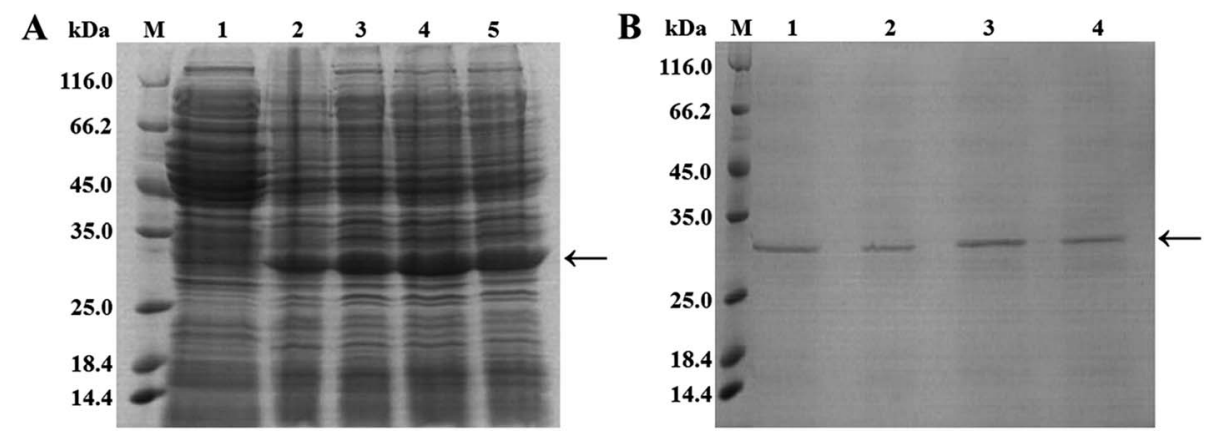

Fig. 1 Analysis of the expression of the WT and mutant PCLs and the purification of the recombinant proteins using SDS-PAGE. (A) SDS-PAGE analysis of the recombinant proteins expressed by E. coli BL21. Lane M: protein molecular weight marker; lane 1: crude protein extract of BL21/ pET-22b; lane 2: crude protein extract of BL21/pET-pclm; lane 3: crude protein extract of BL21/pET-l41p; lane 4: crude protein extract of BL21/ pET-g47i; lane 5: crude protein extract of BL21/pET-141p/g47i. (B) SDS-PAGE analysis of the purified recombinant proteins by Ni-affinity chromatography. Lane M: protein molecular weight marker; lane 1: purified WT; lane 2: purified L41P; lane 3: purified G47I; lane 4: purified L41P/ G47.

G47I, and L41P/G47I retained $11 \%, 44 \%$, and $23 \%$ of the maximal activity after incubation at $45{ }^{\circ} \mathrm{C}$ for $60 \mathrm{~min}$, respectively. Moreover, the approximated half-life $\left(T_{1 / 2}\right)$ values at $35{ }^{\circ} \mathrm{C}, 40{ }^{\circ} \mathrm{C}$, and $45{ }^{\circ} \mathrm{C}$ of the WT and mutant PCLs are presented in Table 1 . The $T_{1 / 2}$ values at $45^{\circ} \mathrm{C}$ for L41P, G47I, and L41P/G47I were 7-, 13-, and 9-fold higher, respectively, than that of the WT. The results demonstrated that the temperature optimum and thermostability of the mutant PCLs was improved
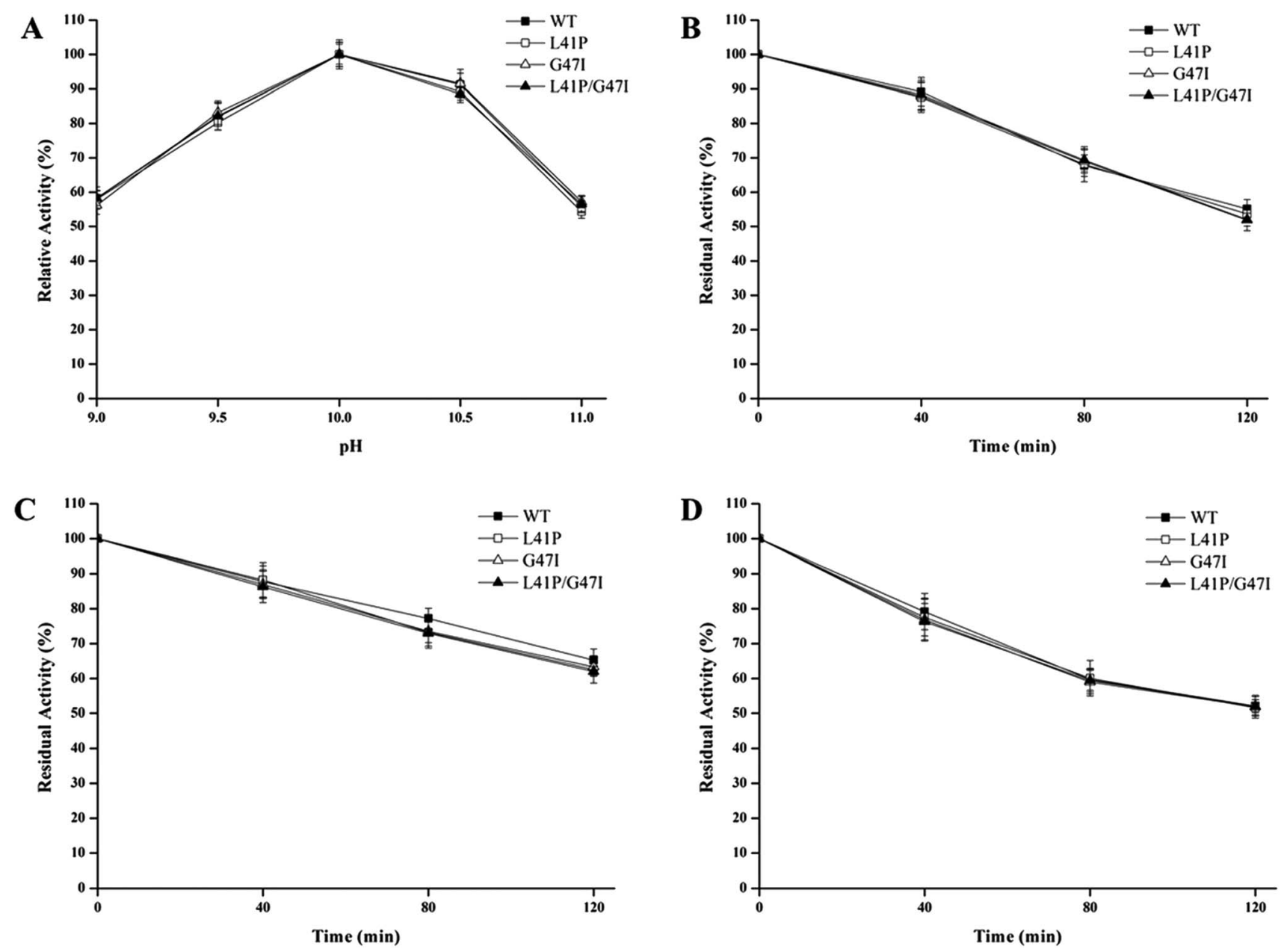

Fig. 2 Effect of pH on the activity of the WT and mutant PCLs (A) and the pH stability of the WT and mutant PCLs at pH 9.0 (B), 10.0 (C), and 11.0 (D). The data presented are the average values of three independent experiments and the error bars indicate the standard deviations. 

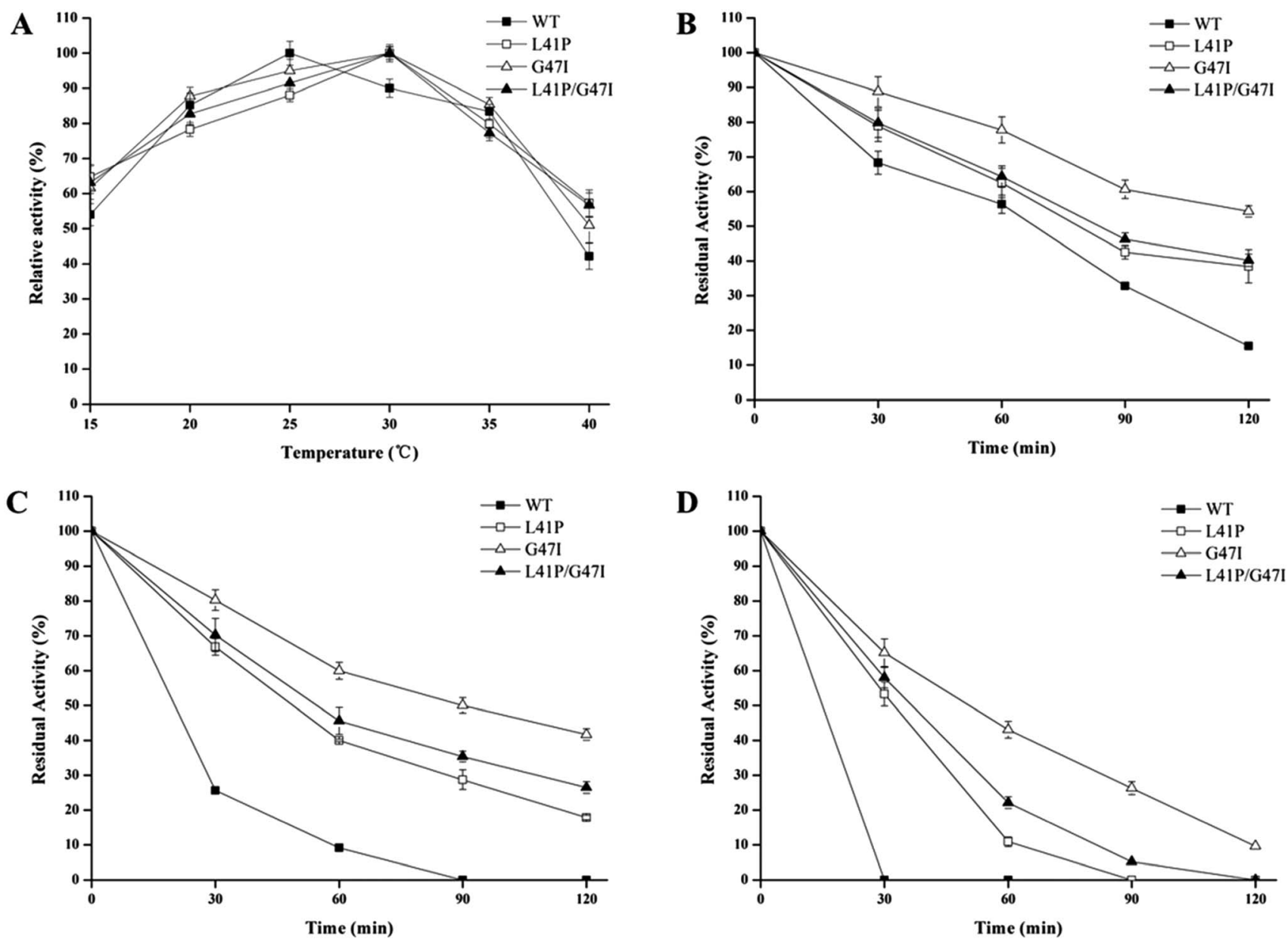

Fig. 3 Effect of temperature on the activity of the WT and mutant PCLs (A) and thermostability of the WT and mutant PCLs at $35^{\circ} \mathrm{C}(\mathrm{B}), 40{ }^{\circ} \mathrm{C}(\mathrm{C})$, and $45^{\circ} \mathrm{C}(\mathrm{D})$. The data presented are the average values of three independent experiments and the error bars indicate the standard deviations.

Table $1 T_{1 / 2}$ values of the WT and mutant PCLs ${ }^{b}$

\begin{tabular}{lrlr}
\hline & \multicolumn{3}{c}{$T_{1 / 2}{ }^{a}(\mathrm{~min})$} \\
\cline { 2 - 4 } Lipases & \multicolumn{1}{c}{$35^{\circ} \mathrm{C}$} & $40{ }^{\circ} \mathrm{C}$ & \multicolumn{1}{c}{$45{ }^{\circ} \mathrm{C}$} \\
\hline WT & $66.7 \pm 1.3$ & $23.4 \pm 0.3$ & $4.7 \pm 0.08$ \\
L41P & $87.3 \pm 1.8$ & $61.1 \pm 1.2$ & $33.2 \pm 0.7$ \\
G47I & $126.0 \pm 2.3$ & $93.5 \pm 1.7$ & $61.0 \pm 1.3$ \\
L41P/G47I & $91.6 \pm 1.5$ & $69.2 \pm 1.6$ & $41.6 \pm 0.9$
\end{tabular}

${ }^{a}$ The $T_{1 / 2}$ values are based on the inactivation profiles depicted in Fig. 3 b-d. ${ }^{b}$ Data are shown as the mean \pm standard deviation $(n=3)$.

after mutation and Gly47Ile was more effective in increasing the PCL stability against high temperatures than Leu41Pro and Leu41Pro/Gly47Ile.

In addition, the properties of L41P, G47I, and L41P/G47, which were determined using $p$-nitrophenyl laurate as the substrate, were consistent with the above results, suggesting that the mutation did not change the catalytic characteristics of the mutant PCLs on a small synthetic substrate and a macromolecular substrate.
So far, a great deal of research on protein engineering for improvement of the thermostability of mesophilic/thermophilic lipases has been reported. For instance, the mutant A251E of Candida antarctica lipase B, designed using the RosettaDesign algorithm, showed a $T_{1 / 2}$ at $50{ }^{\circ} \mathrm{C}$ of $251 \mathrm{~min} .{ }^{34}$ Lipase A from Serratia marcescens underwent site-directed mutagenesis using computational predictions, and the mutants G2P and G59P retained around $90 \%$ activity after being incubated at $50{ }^{\circ} \mathrm{C}$ for $1 \mathrm{~h}^{35}$ The mutant G14S/A15G/V109S of the lipase from Bacillus pumilus, obtained by directed evolution, had a $T_{1 / 2}$ at $50{ }^{\circ} \mathrm{C}$ of 38.5 min. $^{22}$ Compared with its mesophilic and thermophilic counterparts, PCL, a cold-active lipase, exhibited more difficulty in improvement of the thermostability for its structure flexibility. Although the mutant PCLs displayed weaker thermostabilities than the mesophilic/thermophilic WTs and their variants, the thermostability of the mutant PCLs was significantly improved compared to that of PCL WT. In addition, thermo- and alkaline-stable lipases have received attention because they can be applied in a broad range of fields including food production, detergent, paper making, textile, and leather industries, etc. ${ }^{36,37}$ To obtain the mutant PCL with an improved thermostability, a new disulfide bridge was designed in PCL 
Table 2 Kinetic parameters of the WT and mutant PCLs

\begin{tabular}{|c|c|c|c|c|c|c|c|c|c|}
\hline Lipases & \multicolumn{3}{|c|}{ p-Nitrophenyl caprylate (C8) } & \multicolumn{3}{|c|}{$p$-Nitrophenyl laurate (C12) } & \multicolumn{3}{|c|}{ p-Nitrophenyl palmitate (C16) } \\
\hline WT & $0.63 \pm 0.020$ & $2.48 \pm 0.070$ & $0.25 \pm 0.0076$ & $0.87 \pm 0.025$ & $1.72 \pm 0.058$ & $0.51 \pm 0.018$ & $0.43 \pm 0.015$ & $3.15 \pm 0.098$ & $0.14 \pm 0.0045$ \\
\hline L41P & $0.63 \pm 0.018$ & $2.47 \pm 0.077$ & $0.26 \pm 0.0070$ & $0.88 \pm 0.031$ & $1.77 \pm 0.056$ & $0.50 \pm 0.018$ & $0.46 \pm 0.018$ & $3.19 \pm 0.095$ & $0.14 \pm 0.0040$ \\
\hline G47I & $0.64 \pm 0.022$ & $2.41 \pm 0.075$ & $0.27 \pm 0.0066$ & $0.89 \pm 0.028$ & $1.79 \pm 0.063$ & $0.50 \pm 0.015$ & $0.44 \pm 0.020$ & $3.21 \pm 0.090$ & $0.14 \pm 0.0038$ \\
\hline
\end{tabular}

through the substitution of Val248 and Thr251 with Cys to create $\mathrm{V} 248 \mathrm{C} / \mathrm{T} 251 \mathrm{C}$. The $T_{1 / 2}$ values at $35^{\circ} \mathrm{C}$ of WT expressed in $E$. coli, $\mathrm{V} 248 \mathrm{C} / \mathrm{T} 251 \mathrm{C}$ expressed in $E$. coli, WT expressed in $P$. pastoris, and V248C/T251C expressed in P. pastoris, were 20, 90, 5 , and $64 \mathrm{~min}$, respectively, indicating that the disulfide bridge in V248C/T251C could enhance its thermostability. ${ }^{38}$ However, the theoretical basis and background data of the structurefunction relationship at high temperatures on PCL were still limited.

\section{Kinetic parameters of the WT and mutant PCLS}

The kinetic parameters for the WT and mutant PCLs were measured at $\mathrm{pH} 8.0$ and $30^{\circ} \mathrm{C}$ with $p$-nitrophenyl caprylate $(\mathrm{C} 8)$, $p$-nitrophenyl laurate (C12), and $p$-nitrophenyl palmitate (C16) as substrates, respectively (Table 2). The mutant PCLs showed no distinct change in their kinetic parameters including $K_{\mathrm{m}}$, $k_{\text {cat }}$, and $k_{\text {cat }} / K_{\mathrm{m}}$ towards three substrates with different chain lengths in comparison with WT, suggesting that the catalytic pathway was not obviously altered between the WT and mutant PCLs despite the significant variations in their thermostabilities.

\section{The synthesis of ethyl propionate}

Lipases have been used for catalyzing not only the hydrolysis of triacylglycerols but also direct esterification and transesterification reactions to produce lipids. Ethyl propionate, having a pineapple-like odor, is used in perfumery and fragrances. It is also used in the production of pharmaceuticals, agrochemicals, and cosmetics, etc. ${ }^{39}$ Therefore, the present work investigated the PCL catalyzed direct esterification of ethanol and propionic acid into ethyl propionate. The identification and quantitation of ethyl propionate were carried out using gas chromatography-mass spectrometry (GC-MS). In the extracted ion chromatogram (EIC) of 102, a peak with a retention time of 6.379 minutes was observed, which was identified as ethyl propionate after comparison with the NIST 2.0 library spectrum (Fig. 4). The optimized formulation for the synthesis of ethyl propionate from ethanol and propionic acid by G47I is summarized as follows: $250 \mathrm{mmol} \mathrm{L}{ }^{-1}$ ethanol, $200 \mathrm{mmol} \mathrm{L}^{-1}$ propionic acid, $1200 \mathrm{U}$ enzyme, $15 \mathrm{~mL}$ of $n$-nonane, $35{ }^{\circ} \mathrm{C}$, and react for $20 \mathrm{~h}$. Under the ideal synthesis conditions, the conversion of ethyl propionate catalyzed by G47I reached $45 \%$, meanwhile a conversion of $27 \%, 23 \%$, and $8 \%$ was obtained for L41P/G47I, L41P, and WT, respectively. The results reveal that

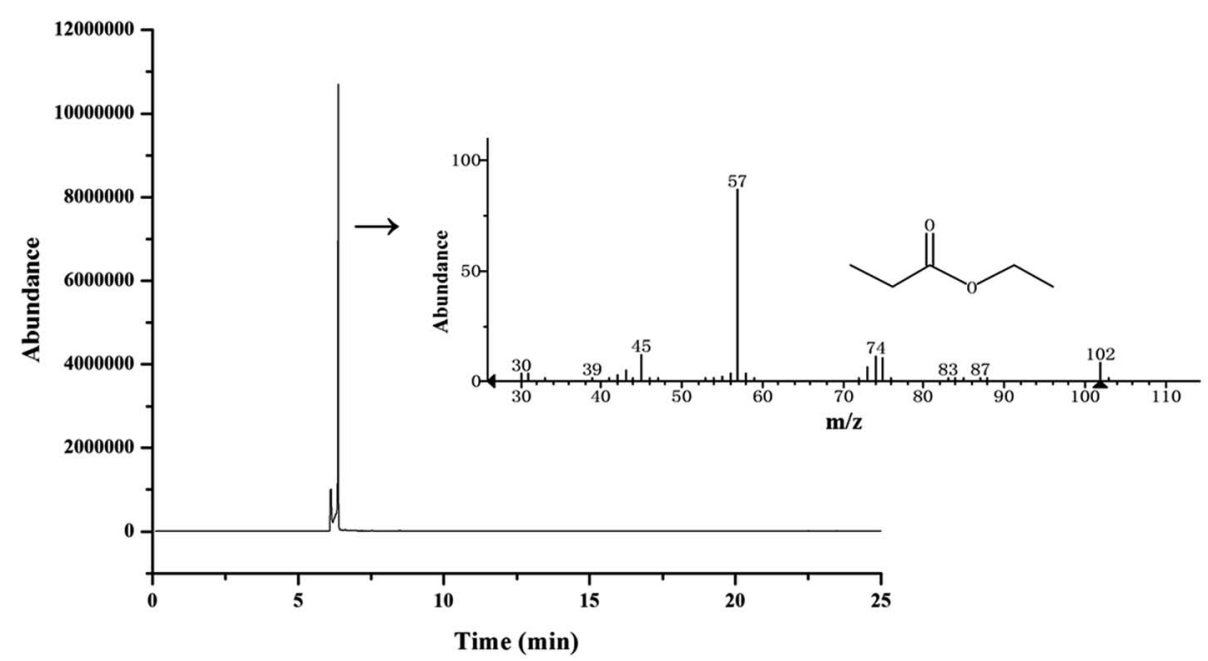

Fig. 4 Extracted ion chromatogram (EIC) of 102 corresponding to ethyl propionate formed by G47I with ethanol and propionic acid as substrates by GC-MS. 
PCL has potential applications in the production of a number of commercially important esters, and the mutation also improved the thermostability for the transesterification activity of PCL.

\section{Far-UV CD spectroscopy of the WT and mutant PCLS}

CD spectroscopy was applied to investigate the secondary structure changes in the WT and mutant PCLs upon thermal inactivation. The CD spectra of the WT and mutant PCLS without incubation revealed a negative peak at 226-229 $\mathrm{nm}$ and a positive maximum at 192-194 $\mathrm{nm}$, which is a typical feature for $\alpha$-helices, whereas a strong positive peak at $194-195 \mathrm{~nm}$ is a typical signature of $\beta$-sheets (Fig. 5A). The results showed that there were no distinct changes in the CD spectra between the WT and mutant PCLs without incubation. The secondary structure content of the WT and mutant PCLs calculated from the CD spectrum was $9.2 \% \alpha$-helix, $46 \% \beta$-sheet, $10.9 \% \beta$-turn, and $33.9 \%$ random coil. When incubated at $45{ }^{\circ} \mathrm{C}$ for $60 \mathrm{~min}$, WT and L41P showed a significant variation in the global peaks in the CD spectrum, while G47I and L41P/G47I retained the positions of the CD peak (Fig. 5B). After incubation, the WT and L41P $\beta$-sheet content decreased from $46 \%$ to $0 \%$ and from $46 \%$ to $11 \%$, respectively, and $\mathrm{G} 47 \mathrm{I}$ and $\mathrm{L} 41 \mathrm{P} / \mathrm{G} 47$ had no change in the content of the secondary structure. The CD spectra results revealed that the mutant PCLs could maintain more $\beta$-sheets at $45{ }^{\circ} \mathrm{C}$ for $60 \mathrm{~min}$ in comparison with WT, which led to the improvements in the thermal stability of the mutant PCLs.

\section{Fluorescence spectroscopy}

Because aromatic residues are highly sensitive to their surrounding environment, valuable information about the changes in the dynamics, intermolecular interactions, and conformation of the enzyme can be obtained using fluorescence spectroscopy. Possible conformational variations can be reflected by the changes in the maximal fluorescence intensity $\left(I_{\max }\right)$ and the maximal emission wavelength $\left(\lambda_{\max }\right)$, which are characteristic in the fluorescence profile of tryptophan residues

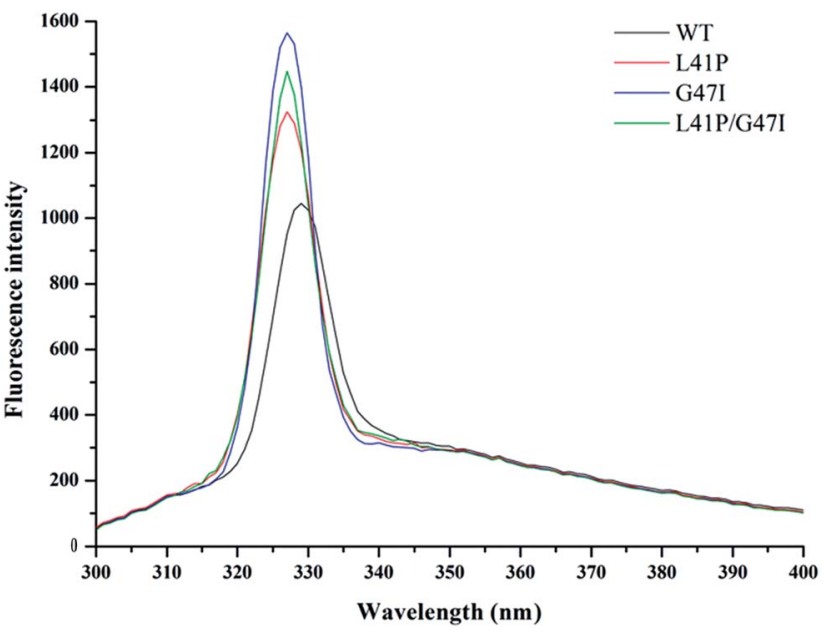

Fig. 6 Fluorescence spectra of the WT and mutant PCLs after incubation in $50 \mathrm{mmol} \mathrm{L}^{-1}$ sodium phosphate buffer $\left(\mathrm{pH} \mathrm{8.0)}\right.$ ) at $45^{\circ} \mathrm{C}$ for $60 \mathrm{~min}$. Each spectrum represents the average of three scans.

in a relatively hydrophobic environment. In order to reveal the conformational differences of the WT and mutant PCLs with incubation at $45{ }^{\circ} \mathrm{C}$ for $60 \mathrm{~min}$, the fluorescence emission spectra using an excitation wavelength of $290 \mathrm{~nm}$ were obtained and are shown in Fig. 6 . The $I_{\max }$ of L41P, G47I, and L41P/G47I increased by $27 \%, 50 \%$, and $36 \%$, respectively, compared with the WT. Meanwhile, WT displayed a $\lambda_{\max }$ of $331 \mathrm{~nm}$, whereas the $\lambda_{\text {max }}$ values of L41P, G47I, and L41P/G47I were slightly blueshifted from $331 \mathrm{~nm}$ to $329 \mathrm{~nm}$. These results suggested an increase in the hydrophobic character at the local microenvironment of the tryptophans, which could be attributed to their higher burial in the mutant PCLs. Hence, the WT and mutant PCLs underwent changes in their tertiary structures, resulting in lower flexibility and higher compactness of the structure of the mutant PCLs as compared with WT. This behaviour was beneficial for the mutant PCLs as this led to an increase in their stability against high temperatures.
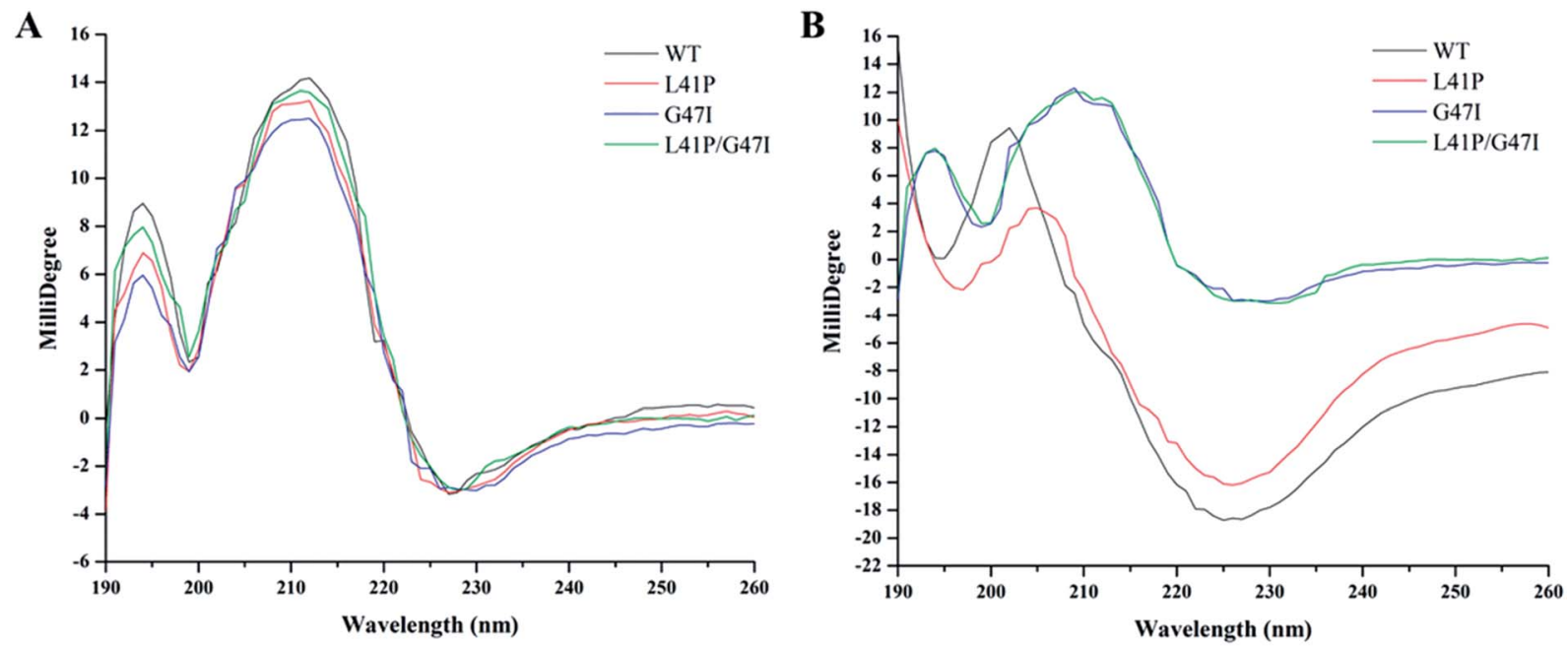

Fig. 5 Far-UV CD spectra of the WT and mutant PCLs in $50 \mathrm{mmol} \mathrm{L}^{-1}$ sodium phosphate buffer (pH 8.0) without incubation (A) and with incubation at $45^{\circ} \mathrm{C}$ for $60 \mathrm{~min}$ (B). Each spectrum represents the average of three scans. 


\section{Structural analysis}

PCL has 99\% homology with the lipase from Penicillium expansum (PEL) in the amino acid sequence, and the crystal structure of PEL has been obtained. ${ }^{40}$ Therefore, the threedimensional structures of the WT and mutant PCLs were built using the structure of PEL as the homology model, using the public website Swiss-Model (http://www.expasy.ch/swissmod/ SWISS-MODEL.html). As Fig. 7 shows, PCL has a modified $\alpha / \beta$ hydrolase fold with seven $\beta$-strands in a parallel $\beta$-sheet surrounded by $\alpha$-helices. Ser132, Asp188, and His241 are identified to be the active sites. The residues at positions 41 and 47 , which are far from the catalytic center of PCL in its tertiary structure, do not directly interact with the active center.

The residue at position 41 is the first residue of the loop which links the $\beta 1$ and $\beta 2$ strands, totally exposed to the solvent.

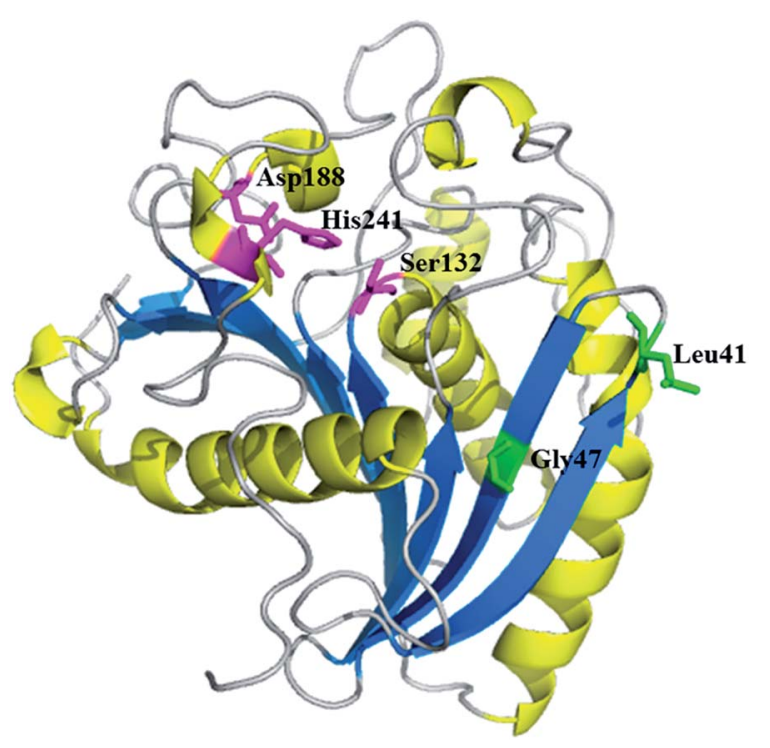

Fig. 7 Modeled three-dimensional structure of PCL. The active sites Ser132, Asp188, and His241 are shown in pink. The mutant positions 41 and 47 are shown in green. The $\alpha$-helices and $\beta$-sheets are colored in yellow and blue, respectively.
It has been suggested that the hydrogen bonding and hydrophobicity/hydrophilicity can play a role in improving the thermostability of lipases. ${ }^{23,41-43}$ Leu41 with one hydrogen bond was involved in a hydrogen bonding network: Leu41 $\leftrightarrow$ Asp44 (Fig. 8A), whereas Pro41 had no hydrogen bond (Fig. 8B). Although one hydrogen bond was undermined, which might slightly decrease the structural stability, the Leu to Pro substitution at position 41 on the protein surface that replaced a hydrophilic side chain with a more hydrophilic group in the exterior of PCL was favourable to increase the structural stability, causing enhancement of the thermostability for L41P. Moreover, proline shows less conformational freedom in comparison with other amino acids through rigidly restricting the rotation of $\mathrm{N}-\mathrm{C} \alpha$ by its pyrrolidine ring, decreasing the entropy during protein unfolding. ${ }^{44}$ Consequently, Pro41 reduced the flexibility of the loop with the conformational change caused by pyrrolidine, which stabilized the structure of PCL at higher temperatures.

The residue at position 47 is located at the third residue of the $\beta 2$ strand in the interior of PCL. Gly47 with two hydrogen bonds was involved in a hydrogen bonding network: Gly47 $\Leftrightarrow$ Ile38 (Fig. 9A), and Ile47 with two hydrogen bonds was involved in a hydrogen bonding network: Ile47 $\Leftrightarrow$ Ile38 (Fig. 9B). Gly47 and Ile47 showed no obvious changes on the hydrogen bonding networks as a result of the similar location and number of hydrogen bonds with them. When Gly was substituted by Ile with a more hydrophobic group at position 47 in the internal PCL, a more fixed tertiary structure was obtained, leading to an improvement of the thermostability for G47I. In addition, it was indicated that during protein unfolding most energy is consumed by breaking the contacts to the residues in an $\alpha$-helix

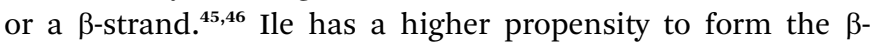
strand in comparison with Gly, which was beneficial for the stabilization of the $\beta 2$ strand in G47I when the replacement of Gly with Ile occurs, resulting in an increase of its structural rigidity for improving the overall stability at higher temperatures.

Generally, beneficial mutations have a synergistic or cumulative effect for the stability of enzymes. ${ }^{45-47}$ In this work, L41P/

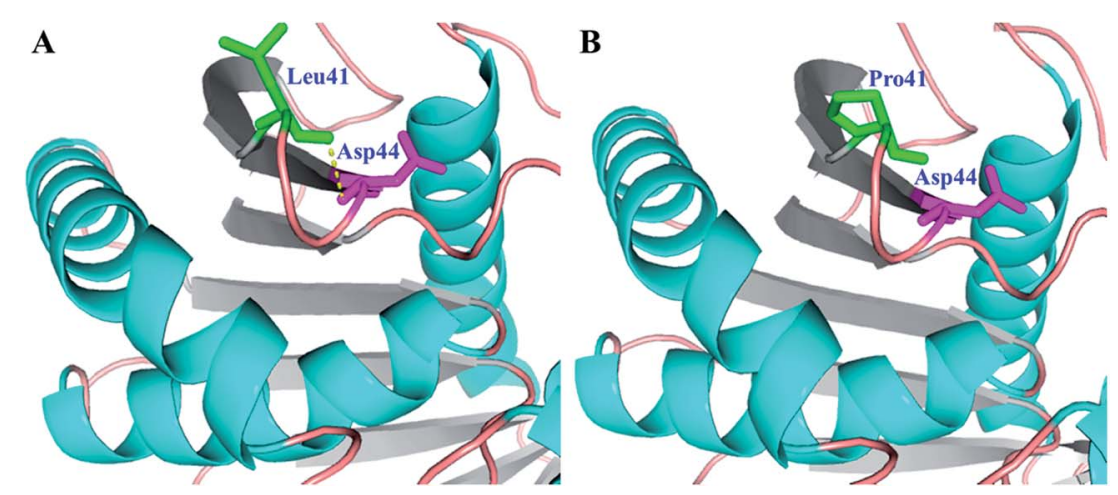

Fig. 8 An expanded view of the residue at position 41 and its surroundings in WT and L41P, respectively. (A) The models of the residue Leu41 and its surroundings. (B) The models of the residue Pro41 and its surroundings. The residues at position 41 are shown in green, and the residues around position 41 are shown in pink. The yellow dotted lines indicate a hydrogen-bonding network around the residue at position 41 . The $\alpha$ helices and $\beta$-sheets are colored in blue and gray, respectively. 


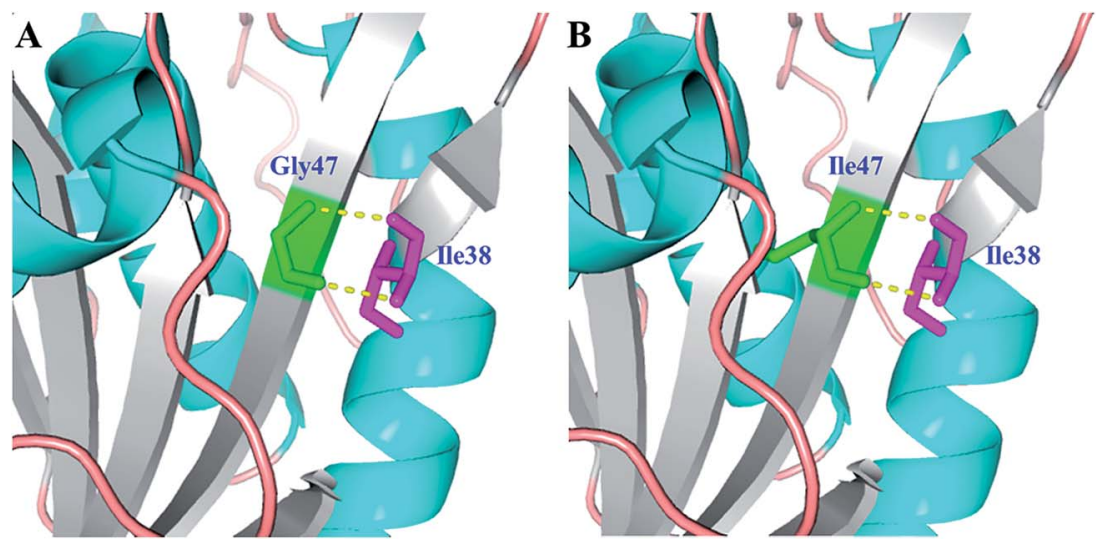

Fig. 9 The expanded view of the residue at position 47 and its surroundings in WT and G47I, respectively. (A) The models of the residue Gly47 and its surroundings. (B) The models of the residue lle47 and its surroundings. The residues at position 47 are shown in green, and the residues around position 47 are shown in pink. The yellow dotted lines indicate a hydrogen-bonding network around the residue at position 47 . The $\alpha$-helices and $\beta$-sheets are colored in blue and gray, respectively.

G47I exhibited better thermostability than L41P, and G47I showed the greatest improvement in thermostability. Although the respective change from Leu/Gly to Pro/Ile at position 41/47 could enhance the structural stability, the combination of the two effects obtained from the simultaneous introduction of Pro/ Ile at position $41 / 47$ did not result in a synergistic or cumulative effect. The residues at positions 41 and 47 were closed, and the residues 41 and 47 with their surroundings are located in the $\beta 1, \beta 1 / \beta 2$ loop, and $\beta 2$, which determines the local conformation of PCL. The interactions of Leu41 and Ile47 with their surroundings had a better effect on the local structural stability in comparison with those of Pro41 and Ile47 with their surroundings, leading to the entire structure of G47I being more stable than that of L41P/G47I. Hence, G47I displayed more improvement in the thermostability compared to L41P/ G47I. In addition, it was shown that position 47 was crucial for the stability of PCL toward high temperatures.

\section{Conclusion}

In conclusion, a novel alkaline-stable lipase with improved thermostability, L41P/G47I, was created by direct evolution using error-prone PCR. Then, the single mutants L41P and G47I were constructed via site-directed mutagenesis. L41P, G47I, and L41P/G47I had a optimum temperature $5{ }^{\circ} \mathrm{C}$ higher than the WT and a 7-, 13-, and 9-times longer half-life at $45{ }^{\circ} \mathrm{C}$, respectively. Furthermore, a novel strategy for the synthesis of ethyl propionate was successfully performed through esterification of ethanol and propionic acid using the WT and mutant PCLs. The results of circular dichroism and fluorescence spectroscopy combined with three-dimensional structure analysis demonstrated that the mutant PCLs showed an improved thermostability as a result of the interactions of hydrophilicity/ hydrophobicity, proline substitution, and helix propensity. This study provides the theoretical basis and background data of the structure-function relationship for improving the thermostability of PCL through protein engineering. Moreover, G47I is a novel thermo- and alkaline-stable lipase and has great potential for industrial applications in food production, detergent, paper making, textile, and leather industries, etc.

\section{Acknowledgements}

This work was supported by the National Natural Science Fund of China (31461143026), the Tianjin Support Plan Program of Science and Technology (16YFZCSY01040), and the Tianjin Natural Science Fund (17JCYBJC23700).

\section{References}

1 K. E. Jaeger and T. Eggert, Curr. Opin. Biotechnol., 2002, 13, 390-397.

2 M. Esteban-Torres, J. M. Mancheñob, B. D. L. Rivas and R. Muñoz, LWT-Food Sci. Technol., 2015, 60, 246-252.

3 A. Maharana and P. Ray, J. Mol. Catal. B: Enzym., 2015, 120, 173-178.

4 C. J. Yao, Y. Cao, S. S. Wu, S. Li and B. F. He, J. Mol. Catal. B: Enzym., 2013, 85-86, 105-110.

5 K. Liu, G. L. Zhao, B. H. He, L. H. Chen and L. L. Huang, Bioresour. Technol., 2012, 123, 616-619.

6 M. B. Ansorgeschumacher and O. Thum, Chem. Soc. Rev., 2013, 42, 6475-6490.

7 M. Nerurkar, M. Joshi and R. Adivarekar, Appl. Biochem. Biotechnol., 2015, 175, 253-265.

8 S. L. Su, R. K. Liew, A. Jusoh, T. C. Cheng, F. N. Ani and H. A. Chase, Renewable Sustainable Energy Rev., 2016, 53, 741-753.

9 S. Kumar, A. Mathur, V. Singh, S. Nandy, S. K. Khare and S. Negi, Bioresour. Technol., 2012, 120, 300-304.

10 R. Abdulla and P. Ravindra, Biomass Bioenergy, 2013, 56, 813.

11 M. Masomian, R. N. Z. R. A. Rahman, A. B. Salleh and M. Basri, Process Biochem., 2013, 48, 169-175.

12 S. Wen, T. W. Tan and H. M. Zhao, J. Biotechnol., 2012, 164, 248-253. 
13 F. Hasan, A. A. Shah and A. Hameed, Enzyme Microb. Technol., 2006, 39, 235-251.

14 R. Sharma, S. K. Soni, R. M. Vohra, L. K. Gupta and J. K. Gupta, Process Biochem., 2002, 37, 1075-1084.

15 S. Emtenani, A. Asoodeh and S. Emtenani, Process Biochem., 2013, 48, 1679-1685.

16 J. Kim, S. H. Jang and C. Lee, Biosci., Biotechnol., Biochem., 2013, 77, 320-323.

17 P. Syal and R. Gupta, Appl. Biochem. Biotechnol., 2015, 176, 110-124.

18 T. L. R. Corrêa, M. P. Zubieta, J. A. Teixeira, M. V. D. Queiroz and E. F. D. Araújo, J. Appl. Microbiol., 2013, 115, 114-124.

19 T. Nakajima-Kambe, N. G. Edwinoliver, H. Maeda, K. Thirunavukarasu, M. K. Gowthaman, K. Masaki, S. Mahalingam and N. R. Kamin, Polym. Degrad. Stab., 2012, 97, 139-144.

20 H. J. Park, J. C. Joo, K. Park and Y. J. Yoo, Biotechnol. Bioprocess Eng., 2012, 17, 722-728.

21 S. Cesarini, C. Bofill, F. I. J. Pastor, M. T. Reetz and P. Diaz, Process Biochem., 2012, 47, 2064-2071.

22 N. Akbulut, M. T. Öztürk, T. Pijning, S. İ. Öztürk and F. Gümüșel, J. Biotechnol., 2013, 164, 123-129.

23 W. N. Niu, Z. P. Li, D. W. Zhang, M. R. Yu and T. W. Tan, J. Mol. Catal. B: Enzym., 2006, 43, 33-39.

24 H. Chahinian, L. Nini, E. Boitard, J. P. Dubès, L. Sarda and L. C. Comeau, Lipids, 2000, 35, 919-925.

25 G. Vanot, D. Valérie, M. C. Guilhem, T. L. R. Phan and L. C. Comeau, Appl. Microbiol. Biotechnol., 2002, 60, 417-419.

26 A. Ibrik, H. Chahinian, N. Rugani, L. Sarda and L. C. Comeau, Lipids, 1998, 33, 377-384.

27 M. C. Wu, Z. K. Qian, P. H. Jiang, T. S. Min, C. R. Sun and W. D. Huang, Lipids, 2003, 38, 191-199.

28 Z. B. Tan, J. F. Li, M. C. Wu, C. D. Tang, H. M. Zhang and J. Q. Wang, World J. Microbiol. Biotechnol., 2011, 27, 27672774.

29 Z. L. Han, S. Y. Han, S. P. Zheng and Y. Lin, Appl. Microbiol. Biotechnol., 2009, 85, 117-126.
30 V. G. H. Eijsink, S. Gåseidnes, T. V. Borchert and d. B. B. Van, Biomol. Eng., 2005, 22, 21-30.

31 M. T. Reetz and J. Halpern, Proc. Natl. Acad. Sci. U. S. A., 2001, 101, 5716-5722.

32 S. Sigurgísladóttir, M. Konráđsdóttir, Á. Jónsson, J. K. Kristjánsson and E. Matthiasson, Biotechnol. Lett., 1993, 15, 361-366.

33 M. M. Bradford, Anal. Biochem., 1976, 72, 248-254.

34 H. J. Park, K. Park, Y. H. Kim and Y. J. Yoo, J. Biotechnol., 2014, 192, 66-70.

35 M. Mohammadi, Z. Sepehrizadeh, A. Ebrahim-Habibi, A. R. Shahverdi, M. A. Faramarzi and N. Setayesh, Enzyme Microb. Technol., 2016, 93-94, 18-28.

36 G. D. Haki and S. K. Rakshit, Bioresour. Technol., 2003, 89, 17-34.

37 X. Zhang, X. Q. Li and L. M. Xia, Biochem. Eng. J., 2015, 103, 263-269.

38 Z. B. Tan, J. F. Li, M. C. Wu and J. Q. Wang, Appl. Biochem. Biotechnol., 2014, 173, 1752-1764.

39 S. S. Kanwar, H. K. Verma, R. K. Kaushal, R. Gupta, S. S. Chimni, Y. Kumar and G. S. Chauhan, World J. Microbiol. Biotechnol., 2005, 21, 1037-1044.

40 C. Bian, C. Yuan, L. Chen, E. J. Meehan, L. Jiang, Z. Huang, L. Lin and M. Huang, Proteins, 2010, 78, 1601-1605.

41 P. Acharya, E. Rajakumara, R. Sankaranarayanan and N. M. Rao, J. Mol. Biol., 2004, 341, 1271-1281.

42 X. Q. Peng, Appl. Biochem. Biotechnol., 2013, 169, 351-358.

43 J. Khurana, R. Singh and J. Kaur, Mol. Biol. Rep., 2011, 38, 2919-2926.

44 C. Zhou, Y. F. Xue and Y. H. Ma, J. Biosci. Bioeng., 2010, 110, 12-17.

45 Y. H. Liu, B. Hu, Y. J. Xu, J. X. Bo, S. Fan, J. L. Wang and F. P. Lu, J. Appl. Microbiol., 2012, 113, 541-549.

46 Y. H. Liu, F. P. Lu, Y. Li, J. L. Wang and C. Gao, Appl. Microbiol. Biotechnol., 2008, 80, 795-803.

47 L. Liu, Z. Deng, H. Yang, J. Li, H. D. Shin, R. R. Chen, G. C. Du and J. Chen, Appl. Environ. Microbiol., 2014, 80, 798-807. 